\title{
Custo corrente por aluno e desempenho acadêmico dos estudantes das universidades federais brasileiras
}

\author{
Joice Garcia de Oliveira \\ https://orcid.org/0000-0003-1384-0976 | E-mail:joicegarciacco@gmail.com \\ Marlon Mendes Silva \\ https://orcid.org/0000-0003-0830-8707 | E-mail:profmarlonmendes@gmail.com \\ João Estevão Barbosa Neto \\ https://orcid.org/0000-0001-5197-2166 | E-mail: joaoestevaobn@face.ufmg.br
}

\section{Resumo}

Objetivo: Identificar a relação do nível de custo corrente por alunodas universidades federais com o desempenho acadêmico dos alunos de graduação.

Método: A amostra foi composta por dados de 62Instituições de Ensino Superior (IES) federais no período de 2010 a 2019,compreendendo 428.175 alunos.A técnica aplicada foi a regressão múltipla com dados em painel. Para medir o desempenho acadêmico do estudante, foi utilizada a nota no Enade,e os gastos das IES foram mensurados pelo custo corrente sem Hospital Universitário (HU).

Resultados: Verificou-se que não há relação estatisticamente significativa entre o custo corrente por aluno e o desempenho acadêmico. Entretanto, destaca-se que as variáveis sociodemográficas: raça, sexo, idade, estado civil, escolaridade da mãe e renda apresentaram relação com o desempenho do aluno.

Contribuições: Este artigo pode contribuir com o desenvolvimento de políticas públicas pelo Governo federal voltadas para a educação. Além disso, as IES podem identificar caminhos para a definição de políticas e tomada de decisões em busca de equilibrar eficiência e eficácia, dados os recursos disponíveis. Contudo, pondera-se sobre o alcance da contribuição deste trabalho, já que a relação custo correntee desempenho não foi significativa. Ademais, espera-se que contribua para a sociedade como meio de controle social aos níveis de custos das IES públicas.

Palavras-chave: Gastos universitários, Desempenho acadêmico, Universidades públicas federais. 


\section{Introdução}

O investimento no ativo humano é primordial para a economia de um Estado. Entre os aspectos elencados para serem investidos no ativo humano, destaca-se a educação formal, visto que, ao obter maior nível de educação, o indivíduo contribui para que a economia tenha um bom desempenho (Schultz, 1960). Isso pode ocorrer, seja pela via do aumento da produtividade individual, seja pelo aumento das chances de ascensão social (Lins, 2013).

Com relação ao contexto educacional brasileiro, a Lei n. ${ }^{\circ 9.394 / 96}$, conhecida como Lei das Diretrizes e Bases da Educação Nacional, em seu Art. 21, define que a educação escolar se compõeda educação básica, formada pela educação infantil, ensino fundamental e ensino médio, e da educação superior. Nas duas últimas décadas, essa última vem se expandindo e ganhando destaque. Segundo o Censo do Ensino Superior (2017), realizado pelo Instituto Nacional de Estudos e Pesquisas Educacionais Anísio Teixeira (Inep), no período compreendido entre 2007 e 2017, o ensino superior privado cresceu $53,1 \%$ e o ensino superior público aumentou $41,7 \%$ no mesmo período.

A educação superior tem como finalidade: i) estimular a criação e estudo científico; ii) formar diplomados das mais diversas áreas; iii) incentivar a pesquisa e investigação científica; iv) promover a

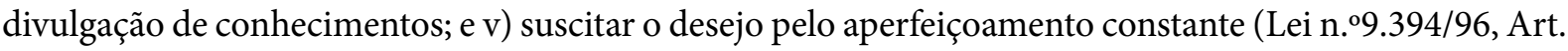
43). Entretanto, para que todas as finalidades do ensino superior sejam atendidas, torna-se necessário o investimento de recursos por parte do governo nas universidades públicas.

Uma das formas de averiguar se o recurso destinado às universidades foi utilizado de maneira eficiente é por meio da análise do desempenho acadêmico dos discentes. Estudos anteriores já discutiram sobre o impacto do volume de recursos na educação, sobretudo no ensino básico. Todavia, no ensino superior, essa temática ainda é pouco explorada e os resultados encontrados são contraditórios, visto que a relação entre gastos institucionais e a performance dos alunos é complexa (Pike, Smart, Kuh\& Hayek, 2006; Dahlvig, Dahlvig\&Chatriand, 2020).

De acordo com Hedges, Laine e Greenwald (1994), por muito tempo os gastos das universidades foram ignorados pela literatura como um fator determinante do desempenho acadêmico dos estudantes. Doravante, estudos internacionais passaram a incluir o nível de recursos disponível para as universidades como variável explicativa do desempenho dos discentes (Pike et al., 2006; Webber \&Ehrenberg, 2010; Pike, Kuh, McCormick, Ethington\&Smart, 2011; Powell, Gilleland\& Pearson, 2012; Rutherford \&Rabovsky, 2014; Hong \&Zimmer, 2016;Dahlvig et al., 2020).

No âmbito nacional, ainda não há consenso sobre a existência de relação direta entre gastos educacionais e desempenho acadêmico no ensino superior. Entretanto, já foi constatada relação indireta positiva por meio da relação entre a qualidade da infraestrutura da instituição de ensino superior e o desempenho acadêmico do discente, já que os recursos investidos na universidade são essenciais para o aperfeiçoamento do capital físico dela (Barbosa, Freire \& Crisóstomo, 2011; Ferreira, 2015; Lemos \& Miranda, 2015).

Nesta linha, diante da escassez de recursos das universidades federais, bem como da necessidade de tais instituições cumprirem suas finalidades educacionais, o objetivo do estudo foi identificar a relação do custo corrente por alunodas universidades federais com o desempenho acadêmico dos alunos de graduação.

A universidade é uma instituição social e como tal exprime de maneira determinada a estrutura e o modo de funcionamento da sociedade como um todo (Chaú, 2003). Assim, este estudo se justifica pelo fato de abordar os recursos aplicados nas instituições de ensino e seus reflexos no desempenho acadêmico e na sociedade, verificando se instituições com maior nível de recursos efetivamente apresentam um maior desempenho. Conforme afirmam Dahlvig et al. (2020), as escolhas institucionais referentes à aplicação dos recursos disponíveis estão correlacionadas ao sucesso e à persistência dos estudantes de graduação. Além disso, o desenvolvimento de estudos que analisam as relações entre a formacomoas universidades gastam seus recursos e o impacto disso na trajetória do aluno destaca-se como uma importante temática diante da responsabilidade de tais instituições (Dahlvig et al., 2020). Destarte, o estudo se justifica por averiguar se as universidades federais estão gerindo adequadamente seus recursos em busca de alcançar o bom desempenho acadêmico dos discentes. 
Espera-se que os resultados deste artigo contribuam com o desenvolvimento de políticas públicas por parte do Governo federal voltadas para a educação,pois à medida que os gastos dessas instituições aumentam, elas devem se esforçar para gerir tais recursos da melhor forma possível. Além disso, as próprias instituições de ensino superior públicas podem identificar caminhos para a definição de políticas e tomada de decisões em busca de um equilíbrio entre eficiência e eficácia,dadosos recursos disponíveis (Dahlvig et al., 2020). Ademais, espera-se que o estudo contribua com a sociedade como meio de controle social e atenção aos níveis de custos das instituições públicas de ensino superior do país.

\section{Revisão de Literatura}

\subsection{Desempenho acadêmico e gastos inerentes às instituições de ensino superior}

O desempenho acadêmico pode ser definido como a avaliação do desenvolvimento e do aprendizado dos alunos, ou seja, é um método de análise que permite julgar quão bem os discentes alcançam os objetivos acadêmicos (Braga \& Franco, 2004).

No Brasil, métricas como o Índice Geral de Cursos Avaliados da Instituição (IGC) e aTaxa de Sucesso na Graduação (TSG), ambos em nível institucional, ou ainda o Conceito Preliminar de Curso (CPC), em nível de um curso específico,visam avaliar a qualidade das instituições de ensino superior(INEP, 2020). Outra métrica de desempenho dos estudantes e instituições é o Exame Nacional de Desempenho dos Estudantes (Enade).

No âmbito nacional, o Sistema Nacional de Avaliação da Educação Superior (Sinaes), que objetiva avaliar a qualidade da educação, realiza anualmente o Enade, que avalia os estudantes em relação às diretrizes curriculares do respectivo curso (Lei n.10.861/2004).O Enadevisa medir as diferentes áreas de conhecimento em avaliações trienais e utiliza-se da prova que objetivaavaliar os conhecimentos específicos da área do curso, bem como conhecimentos em outras áreas de formação geral. Ainda na realização do exame, existe o questionário de impressões sobre a prova, perfil do estudante e o questionário do coordenador do curso, visando avaliar, dentre outros, o alinhamento ao projeto pedagógico do curso (Lei n. $\left.{ }^{\circ} 10.861 / 2004\right)$.

A performance do estudante pode ser resultado de diversos aspectos ligados ou não diretamente a ele. Entre os principais aspectos que influenciam a performance do aluno, tem-se: i) aspectos relacionados às características individuais do discente, como inteligência, habilidade e competência; ii) aspectos sociodemográficos, como sexo, idade, renda familiar e formação de base em instituição pública ou privada; iii) aspectos ligados à infraestrutura da universidade, como qualidade do acervo da biblioteca e acesso à internet; e iv) aspectos referentes à qualidade do ensino, como qualificação acadêmica do corpo docente, professores com conteúdo atualizado e diferentes técnicas de ensino (Magalhães \& Andrade, 2006; Araújo, Camargos, Camargos \& Dias, 2013; Miranda, Lemos, Pimenta \& Ferreira, 2015).

Para a universidade conseguir manter infraestrutura adequada e corpo docente qualificado ao longo dos anos, torna-se necessário um incremento no gasto público com a educação superior. A falta desse incremento pode resultar na redução do desempenho geral da universidade, além de um excesso de alunos nas salas de aula. Ademais, a baixa performance do discente também tem impacto na continuidade do curso, podendo ter como consequência o abandono ou o atraso nos estudos gerando, por exemplo, sentimento de frustração (Fagundes, Luce\&Espinar, 2014).

No contexto nacional, o Censo do Ensino Superior (INEP, 2017) apontou que a educação superior apresentou uma queda de $7 \%$ na oferta de cursos de graduação por parte das universidades públicas federais no período de 2014 a 2016. Tal fato ressalta a importância do investimento em tais instituições para a manutenção do ensino e do nível de qualidade e desempenho dos alunos. 
Dados em relação às despesas em universidades públicas no Brasil apresentados pelo Banco Mundial (2017) apontam que o estudante de universidades públicas no Brasil custa de duas a três vezes mais que estudantes em universidades privadas. Os dados do relatório denominado "Revisão das Despesas Públicas" indicam que, entre 2013 e 2015, o custo médio anual por estudante em universidades privadas sem e com fins lucrativos foi de aproximadamente $\mathrm{R} \$ 12.600$ e $\mathrm{R} \$ 14.850$, respectivamente. Ainda no relatório, para universidades federais, a média foi de $\mathrm{R} \$ 40.900$; para universidades estaduais, aproximadamente $\mathrm{R} \$ 32.200$; e o custo por aluno dos institutos federais de aproximadamente $\mathrm{R} \$ 27.850$. No relatório ainda é indicadauma possibilidade de limitar os gastos por alunos aos níveis dos gastos das universidades mais eficientes no país (Banco Mundial, 2017).

Contudo, instituições de ensino superior públicas podem incorrerem somas que não são aplicáveis às instituições privadas, porexemplo, gastos com pessoal inativo, hospitais universitários, entre outros. Adicionalmente, tem-se o fato das atividades de pesquisa realizadas pelasuniversidades públicas, um gasto não encontrado na maior parte das universidades privadas. De acordo com Moura (2019), mais de 95\% da produção científica do Brasil nas bases internacionais é feita pelas universidades públicas. Assim, comparar os custos dos alunos dentro de um mesmo grupo de instituições torna-se mais coerente.

As IES contemplam diversos processos que utilizam diferentes recursos para atender às suas finalidades. Tais recursos, como materiais de uso e consumo, gastos de infraestrutura e mão de obra, resultam em conhecimento de formação profissional, produção científica e tecnológica (Reis \& Reis, 2013). Dessa forma, para atender às suas finalidades, as instituições de ensino superior necessitam de uma estrutura organizacional e de investimentos e manutenção alinhados a uma boa gestão de recursos para a sustentabilidade e o alcance dos objetivos acadêmicos, econômicos e sociais (Reis \& Reis, 2013).

Além disso, os recursos das instituições públicas de ensino superior são financiados pela sociedade por meio do pagamento de tributos. Assim os gestores das IES possuem a responsabilidade de alocar tais recursos de modo eficiente e eficaz para a manutenção do funcionamento dessas instituições e como compromisso com o desenvolvimento acadêmico e da sociedade (Chiau\&Panucci-Filho, 2014).

\subsection{Estudos anteriores relacionando desempenho dos discentes e gastos educacionais}

Trabalhos empíricos já buscaram averiguar a relação existente entre o desempenho dos estudantes e os gastos educacionais. Pike e Robbins (2019) comentam que diversos estudos já apontaram fatores que podem ter relação com o desempenho do discente, tais como: sexo, raça, status socioeconômico, notas do ensino médio, tipo da instituição (pública ou privada), engajamento acadêmico e social e se o discente trabalha durante a graduação. Os autores comentam ainda que a duração do curso, o tamanho da instituição (quantidade de alunos) e o fato dela possuir mestrado ou doutorado também poderiam influenciar no desempenho dos estudantes. No caso brasileiro, os estudos que se destacam são listados a seguir.

Barbosa et al. (2011) analisaram possíveis relações entre indicadores de gestão e desempenho discente. Os autores identificaram que o custo por aluno, conceito dos cursos de pós-graduação e índice de qualificação do corpo docente têm efeito positivo sobre o desempenho discente. Contudo, os autores encontraram que uma maior proporção de professores e funcionários com relação ao contingente discente não influenciou no desempenho dos alunos.

Ferreira (2015) identificou variáveis significativas na explicação do resultado no Enade2012 pelos alunos de Ciências Contábeis. A autora apontou que as características e atitudes dos alunos são as maiores responsáveis para determinação do desempenho acadêmico e que apenas $10 \%$, aproximadamente, ficam a cargo das variáveis institucionais (docente e IES). A autora destaca que isso pode estar relacionado com o fato de que as instituições públicas tenham maior desempenho no Enad e não apenas pelas condições institucionais, mas sim pelo perfil de alunos que ingressaram na IES pública. 
Lemos e Miranda (2015) identificaram quais variáveis influenciam o desempenho acadêmico dos discentes com base nas edições do Enad e dos anos de 2009 e 2012 do curso de Ciências Contábeis. Os autores destacaram que os principais pontos em que as entidades de ensino superior devem investir para obterem melhores resultados no Enad e são: qualificação docente (titulação e formação pedagógica), investimento em infraestrutura e ampliação da quantidade de professores com dedicação exclusiva.

Rocha e Funchal (2019) avaliaram as relações entre os custos escolares, a organização da oferta escolar e o desempenho de escolas públicas, por meio do Exame Nacional do Ensino Médio (Enem). Os autores apontaram uma grande oscilação nos custos escolaresentre unidades, identificando desigualdades na distribuição dos recursos financeiros. Contudo, os custos escolares apresentaram baixa capacidade de explicação dos resultados das escolas no Enem, apontando indícios de que uma maior quantidade de recursos não se traduz necessariamente em melhores resultados em termos de desempenho escolar.

No contexto internacional, Pike et al. (2011) destacaram a importância da accountability no ensino superior no tocante à utilização dos recursos de maneira eficiente para promover resultados na aprendizagem dos alunos. O estudo foi conduzido com dados de 171 instituições públicas de ensino superior nos Estados Unidos, no qual os autores examinaram as relações entre gastos com educação, o engajamento dos alunos e o resultado na aprendizagem deles. Os resultados indicaram que o nível de gastos teve uma relação moderada com a aprendizagem do aluno.Entretanto, tal relação apresentou um maior efeito para estudantes que estavam no primeiro ano do curso e um efeito mais modesto para alunos dos anos finais.

Rutherford e Rabovsky (2014) buscaram analisar a eficácia das políticas de educação como um mecanismo para melhorar a persistência e o sucesso dos estudantes de graduação em mais de 500 instituições de ensino superior norte-americanas, ao longo de um período de 18 anos. Os resultados encontrados apontaram uma relação negativa entre a raça dos estudantes (negros e hispânicos) e o desempenho, contudo, foi encontrada uma relação positiva entre o nível de custos por aluno e sua performance na graduação.

Hong e Zimmer (2016) avaliaram o impacto das despesas de infraestrutura no desempenho dos alunos no período de 1996 a 2009, referente às escolas do estado de Michigan, nos Estados Unidos. Os autores encontraram que os níveis de despesas de infraestrutura influenciam no desempenho dos alunos. Todavia, o efeito não é notado no curtoprazo, sendo necessários, no mínimo, quatro anos para notar tal relação.

Pike e Robins (2019) examinaram os efeitos de características institucionais, características dos estudantes e os gastos institucionais sobre as taxas de conclusão da graduação em 326 instituições de ensino superior norte-americanasno período de 2002 a 2006. Os autores encontraram uma relação positiva entre os gastos com instrução e o percentual de estudantes do sexo feminino nas taxas de conclusão da graduação nas instituições. Os autores encontraram também uma relação negativa entre o percentual de estudantes negros e as taxas de conclusão da graduação.

Dahlvig et al. (2020) investigaram as correlações entre os gastos de 135 instituições de ensino superior norte-americana se as taxas de retenção e conclusão da graduação dos alunos. Os resultados encontrados pelos autores apontaram que os gastos com pessoal docente, gastos com suporte (manutenção de laboratórios, biblioteca e gastos administrativos) e gastos com pesquisa apresentaram alta correlação com as taxas de alunos que concluem o curso superior.

Observou-se que ainda não há consenso na literatura brasileira e internacional da influência dos recursos gastos em relação a um maior desempenho do aluno na educação superior. Dessa forma, este trabalho pretendeu contribuir para a discussão sobre esse tema proporcionando novos achados sobre a relação entre custo corrente por aluno e desempenho. Tendo em vista os estudos anteriores, elaborou-se a seguinte hipótese de pesquisa:

H1: Universidades públicas que incorrem em maiores custos correntes por aluno tendem a ter melhor desempenho no Enade. 
Apesar dos estudos apontarem que fatores sociais tendem a ser mais influentes sobre o desempenho do discente, espera-se que essa hipótese se confirme devido à importância da aplicação de recursos na manutenção das atividades da universidade para que os alunos obtenham melhores níveis de desempenho.

\section{Metodologia}

Este artigo se classifica, segundo seus objetivos, como descritivo. Quanto aos procedimentos, o estudo é classificado como documental (Martins \&Theóphilo, 2009), visto que os dados foram coletados em bases de dados secundários. Quanto à abordagem, é de natureza quantitativa por se tratar de uma pesquisa que utiliza métodos estatísticos na construção de modelos econométricos.

Tendo em vista que o desempenho acadêmico do estudante sofre influência de diversos fatores, dificilmente poderia ser estabelecida uma medida exata do seu desempenho. Portanto, torna-se necessário estabelecer uma proxy para análise (Miranda et al., 2015).Dessa forma, neste estudo utilizou-se da nota do Enade para medir o desempenho dos discentes e as respostas ao questionário do perfil do estudante para caracterizar o perfil sociodemográfico dos alunos de graduação das universidades federais brasileiras.

A amostra foi composta por 62 universidades federais brasileiras e o período de análise foi de 2010 a 2019,com dados anuais. Os dados referentes ao desempenho acadêmico e perfil sociodemográfico dos alunos disponíveis nos relatórios do Enade foram coletados no site do Inep. Os dados foram tratados por meio do software Excel. Foram excluídos da amostra do estudo os alunos que não estiveram presentes no exame, que não tiveram resultado válido, que não responderam ao questionário sociodemográfico ou que obtiveram nota no exame igual a zero. Assim, tais dados representam as respostas de 428.175 estudantes que realizaram o exame no período de análise.Os dados relativos aos custos correntes sem HU por aluno equivalente foram coletados nos relatórios anuais das IES disponíveis no site do Tribunal de Contas da União(TCU). Devido ao efeito da inflação nos custos correntes anuais, a variável custos correntes sem HU foi deflacionada pelo Índice Nacional de Preços ao Consumidor Amplo (IPCA). Esse índice foi escolhido em virtude de englobar uma parcela maior da população, visto que aponta a variação do custo de vida médio de famílias com renda mensal de 1 e 40 salários mínimos (IBGE, 2020). Os dados relativos ao IPCA foram coletados no site do IBGE.

Quanto à análise dos dados, utilizou-se da estatística descritiva para verificar a média, desviopadrão e o coeficiente de correlação do desempenho dos discentes do ensino superior e, principalmente, dos recursos aplicados nas universidades públicas federais para analisar se existe grande discrepância entre os gastos das universidades brasileiras.

Para verificar o nível de recursos utilizados pelas IES e o desempenho alcançado no Enade, aplicouse a técnica de índices-padrão em busca de comparar os resultados de uma determinada instituição de ensino com o padrão das demais, observando se a instituição está melhor, similar ou pior que o padrão da categoria a qual pertence (Matarazzo, 2008). Os quartis para o desempenho acadêmico foram divididos em: $1^{\circ}$ quartil: insatisfatório; $2^{\circ}$ quartil: regular; $3^{\circ}$ quartil: bom; e $4^{\circ}$ quartil: excelente. Já para a variável custos correntes sem $\mathrm{HU}$ por aluno equivalente, os quartis foram distribuídos em: $1^{\circ}$ quartil: muito baixo; $2^{\circ}$ quartil: baixo; $3^{\circ}$ quartil: médio; e $4^{\circ}$ quartil: alto.

Por fim, foi realizada regressão múltipla com dados em painel para verificar a existência de impacto dos custos das universidades no desempenho acadêmico dos discentes.Além dessas, foram consideradas as variáveis de controle que caracterizam o perfil sociodemográfico dos discentes do último ano das universidades federais que realizaram o Enadeno período analisado. As variáveis empregadas no modelo, bem como suas proxies estão descritas na Figura 1. O modelo foi estimado com o auxílio do software STATA. 


\begin{tabular}{|c|c|c|}
\hline Grupos & Variáveis & Proxies \\
\hline $\begin{array}{l}\text { 1. Desempenho da } \\
\text { universidade no ENADE }\end{array}$ & Variável Dependente (ENADE) & $\begin{array}{l}\text { Média simples da pontuação dos discentes } \\
\text { concluintes da universidade no ENADE }\end{array}$ \\
\hline $\begin{array}{l}\text { 2. Custo corrente sem hospital } \\
\text { universitário por aluno }\end{array}$ & Custo corrente (CUSTOS) & $\begin{array}{l}\text { Custo corrente sem hospital universitário dividido } \\
\text { pelo número de alunos equivalentes deflacionado } \\
\text { pelo IPCA. Ajustar a ordem do texto: o que é } \\
\text { deflacionado é o custo e não o número de alunos. }\end{array}$ \\
\hline \multirow{6}{*}{ 3. Variáveis de Controle } & Idade (IDADE) & $\begin{array}{l}\text { Média da idade dos discentes que realizaram a prova } \\
\text { do ENADE medida em anos. }\end{array}$ \\
\hline & Alunos por sexo (SEXFEM) & $\begin{array}{l}\text { Percentual de alunas do sexo feminino concluintes do } \\
\text { curso de ensino superior. }\end{array}$ \\
\hline & Estado Civil (SOLTEIRO) & $\begin{array}{l}\text { Percentual de alunos declarados como solteiros do } \\
\text { total de alunos da universidade que realizaram a } \\
\text { prova do ENADE. }\end{array}$ \\
\hline & Alunos por raça/cor (RAÇA) & $\begin{array}{l}\text { Percentual de cor/raça do total de alunos da } \\
\text { universidade que realizaram a prova do ENADE. }\end{array}$ \\
\hline & $\begin{array}{l}\text { Escolaridade da mãe do aluno } \\
\text { nível médio (ESCMED) } \\
\text { Escolaridade da mãe do aluno } \\
\text { nível graduação (ESCGRAD) }\end{array}$ & $\begin{array}{l}\text { Proporção de alunos concluintes do curso de ensino } \\
\text { superior, alocados segundo as seguintes faixas sobre } \\
\text { a escolaridade da mãe: completou o Ensino Médio, } \\
\text { mas não terminou a faculdade (ESCMED); completou } \\
\text { a faculdade (ESCGRAD). }\end{array}$ \\
\hline & $\begin{array}{l}\text { Renda familiar do estudante } \\
\text { (RENDAATE1.5) } \\
\text { Renda familiar do estudante } \\
\text { (RENDA1.5A3) } \\
\text { Renda familiar do estudante } \\
\text { (RENDA3A4.5) } \\
\text { Renda familiar do estudante } \\
\text { (RENDA4.5A6) }\end{array}$ & $\begin{array}{l}\text { Proporção de alunos concluintes do curso de ensino } \\
\text { superior, com renda familiar segundo as seguintes } \\
\text { faixas: Até } 1,5 \text { salário mínimo (RENDAATE1.5); de } 1,5 \text { a } \\
3 \text { salários mínimos (RENDA1.5A3); de } 3 \text { a } 4,5 \text { salários } \\
\text { mínimos (RENDA3A4.5); de } 4,5 \text { a } 6 \text { salários mínimos } \\
\text { (RENDA4.5A6) }\end{array}$ \\
\hline
\end{tabular}

Figura 1. Descrição das variáveis utilizadas nos modelos de regressão

Fonte: adaptada de Rocha e Funchal (2019).

Em relação aos gastos na universidade, de acordo com Pike et al. (2011), no nível da instituição de ensino, acredita-se que alguns atributos como as despesas educacionais estariam positivamente relacionadas ao engajamento e ao aprendizado dos estudantes. Além disso, Hong e Zimmer (2016) destacam que instituições de ensino com níveis de custos mais elevados poderiam oferecer ambientes mais seguros, limpos, espaçosos e com boa iluminação, o que tornaria mais fácil a concentração, proporcionando aos alunos e professores maior empenho e disposição nos estudos. Além disso, os autores comentam que os professores valorizam as instituições com melhores instalações e, dessa forma, essas instituições poderiam empregar melhores professores, o que poderia contribuir para o desempenho dos alunos. Assim, espera-se que o total docusto da instituição apresente uma relação positiva com o desempenho dos estudantes.

Destaca-se a utilização do custo correntesem hospital universitário por aluno como proxy dos recursos gastos na universidade (Figura 2). A justificativa é que este indicador considera as despesas correntes (manutenção e funcionamento) de todas as unidades gestoras, representando o volume de recursos financeiros aplicados nas universidades federais para a geração das atividades de ensino, pesquisa e extensão. Desse modo, as despesas de capital não foram consideradas, uma vez que irão gerar resultados quetrarão benefícios ao longo prazo, impactando, assim, o desempenho de futuros alunos. 


\author{
CUSTO CORRENTE SEM HU (HOSPITAIS UNIVERSITÁRIOS) \\ (+) Despesas correntes do órgão Universidade, com todas as UGs, inclusive hospitais universitários, se houver \\ (-) $100 \%$ das despesas correntes totais do(s) hospital(is) universitário(s) e maternidade \\ (-) Aposentadorias e Reformas do órgão Universidade \\ (-) Pensões do órgão Universidade \\ (-) Sentenças Judiciais do órgão Universidade \\ (-) Despesas com pessoal cedido - docente do órgão Universidade \\ (-) Despesas com pessoal cedido - técnico-administrativo do órgão Universidade \\ (-) Despesa com afastamento País/Exterior - docente do órgão Universidade \\ (-) Despesa com afastamento País/Exterior - técnico-administrativo do órgão Universidade
}

Figura 2. Fórmula do custo corrente sem HU

Fonte: adaptada de TCU (2010).

Sobre a variável idade, é esperada uma relação positiva da variável com o desempenho, dado que estudantes mais velhos tendem a apresentar um melhor desempenho no Enade (Santos, 2012). Além disso, Eikner e Montondon (2006) afirmam que a idade é um indicador de maturidade. Assim, alunos maduros teriam maior concentração e, consequentemente, tenderiam a obter melhor desempenho se comparado a estudantes mais novos. Os autores acreditam ainda que o discente mais velho tem maior conhecimento prévio, podendo acrescentar no conhecimento adquirido na graduação e impactando no resultado dos exames acadêmicos.

Em relação à raça, Ferreira (2015) afirma que essa característica tem impacto no desempenho acadêmico do estudante quando o país não oferece condições semelhantes de acesso à educação a todas as raças. O Brasil se encaixa neste cenário, pois há predominância de brancos que cursam ou já cursaram uma graduação. Dessa forma, espera-se que discentes brancos obtenham melhor desempenho que estudantes das demais raças.

A escolaridade da mãe ou responsável pelo aluno também pode influenciar no seu desempenho acadêmico. Segundo Bandeira, Rocha, Freitas, Del Prette e Del Prette (2006), a escolaridade dos pais pode ser considerada um indicador de status social, já que famílias com renda mais elevada têm maiores condições de investir na educação e aumentar o nível educacional. Como efeito, responsáveis que tenham cursado graduação ou pós-graduação têm mais propriedade para orientar os filhos a cursarem o ensino superior e se dedicarem da melhor maneira possível aos estudos.

Sobre o estado civil, Ferreira (2015) destaca que estudantes solteiros tendem a apresentar desempenho menor que estudantes casados. Santos (2012) também apontou uma relação negativa entre o fato do estudante ser solteiro e seu desempenho. A autora comenta que isso possivelmente pode ocorrer devido aos estudantes solteiros fazerem escolhas que podem reduzir o tempo dedicado aos estudos, ou ainda pela própria maturidade desses estudantes quando comparados com os casados. Por outro lado, Andrade e Corrar (2008) averiguaram que os solteiros têm melhor desempenho comparativamente aos casados e Masasi (2012) constatou que o estado civil não influencia no desempenho acadêmico do aluno. Como pode ser observado, e de acordo com Miranda et al. (2015), resultados diferentes são encontrados na literatura sobre a relação do estado civil com rendimento acadêmico.

Quanto à renda familiar, Santos (2012) destaca que um aumento no nível de renda teria um impacto no desempenho. Além disso, à medida que a renda do estudante aumenta, seu desempenho também incorre em um impacto positivo. Ademais, Ferreira (2015) indicou que alunos que com alta renda familiar tendem a apresentar desempenho superior quando comparados com alunos de menor renda familiar.

Em relação ao sexo, os estudos de Rangel e Miranda (2016) e Pike e Robins (2019) indicam que estudantes do sexo feminino tendem a apresentar melhor desempenho que estudantes do sexo masculino. Brandão, Silva e Loureiro (2017) destacam que em um contexto de desigualdade de direitos entre os sexos, as mulheres buscam adotar maneiras que facilitem o bom desempenho acadêmico como estratégia para lidar com esse cenário. Além disso, as autoras destacam que tal fato ocorreria nas áreas de humanas, exatas e biológicas no ensino superior. 
Tendo em vista as variáveis propostas, a equação da regressão múltipla com dados em painel é representada pela equação 1:

$$
\begin{aligned}
\text { ENADE }_{i t}=\beta_{0} & +\beta_{1} \text { CUSTOS }_{i t}+\beta_{2} I D A D E_{i t}+\beta_{3} \text { SEXFEM }_{i t}+\beta_{4} \text { SOLTEIRO }_{i t}+\beta_{5} R A C A_{i t} \\
& +\beta_{6} \text { ESCOLARIDADE }_{i t}+\beta_{7} \text { RENDA }_{i t}+u_{i}+\varepsilon_{i t}
\end{aligned}
$$

Onde:

- $E N A D E_{i t}$ : variável dependente do modelo;

- $\quad \beta_{0}$ : coeficiente angular da regressão;

- CUSTOS $_{\text {it }}$ : custo corrente sem HU realizado pela universidade $i$ no tempo $t$;

- $I D A D E_{\text {it }}$ : idade dos alunos da universidade $i$ no tempo $t$;

- $\quad S E X F E M_{\text {it }}$ : sexo feminino dos alunos da universidade $i$ no tempo $t$;

- SOLTEIRO it $^{3}$ : alunos solteiros da universidade $i$ no tempo $t$;

- $R A C A_{\text {it }}$ : raça dos alunos da universidade $i$ no tempo $t$;

- ESCOLARIDADE $E_{\text {it }}$ : escolaridade da mãe dos alunos da universidade $i$ no tempo $t$;

- $R E N D A_{\text {it }}$ : renda familiar dos alunos da universidade $i$ no tempo $t$;

- $u_{i}$ : efeito individual específico não observável (termo de erro efeitos fixos); $\mathrm{e}$

- $\varepsilon_{i t}$ : erro usual da regressão.

Para verificar a adequabilidade do modelo, foram realizados alguns testes após a estimação do modelo pooled. Primeiramente, para avaliar a existência de multicolineariedade entre as variáveis explicativas empregadas no modelo,foi executado o teste de Fator de Inflação da Variância (VIF). Em seguida, foi verificada a forma funcional do modelo por meiodo teste de Ramsay, também conhecido como teste RESET. Por fim, o teste de Doornik-Hansen avaliou a normalidade dos resíduos, em quea hipótese nula deste teste admite que os resíduos têm distribuição normal.

Em seguida, foram realizados os testes referentes à escolha do modelo de regressão em dados em painel para definir o mais adequado para este estudo, sendo eles: teste de Chow, teste de Breusch-Pagan e teste de Hausman. Após a determinação do melhor modelo, foi avaliada a ocorrência de autocorrelação e heterocedasticidade, sendo utilizados os testes de Wooldridge, que admite como hipótese nula a não existência de autocorrelação de ordem 1 e de Likelihood-ratio, tendo como $\mathrm{H}_{0}$ que os erros são homocedásticos.

Sobre o tratamento de outliers, aplicou-se a técnica de winsorização, na qualaquelas observações que são consideradas outliers, ao invés de serem excluídas da amostra, têm seusvalores substituídos pelo último valor aceitável dentro do intervalo de aceitação. Assim, valores muito baixos são substituídos pelo menor valor que não é considerado outlier e valores muito elevados são substituídos pelo maior valor aceito no intervalo sem ser considerado outlier.

\section{Resultados}

\subsection{Estatística Descritiva}

Para caracterizar a amostra do estudo, a base de dados foi segregada por áreas de avaliação, sendo que os dados do estudo representaram os três grupos dos ciclos de avaliação do Enade de acordo com as áreas de conhecimento. Segundo a Tabela 1, o grupo mais representativo na amostra foi o de bacharelado nas áreas de ciências exatas, áreas afins e licenciaturas, totalizando 210.596 alunos. A quantidade expressiva de alunos desse grupo pode ser explicada devido à abrangência de cursos no grupo e também pelo fato de que os cursos de licenciaturas nas IES analisadas ofertam grande número de vagas no país. 
Tabela 1

Alunos por grupos de avaliação no ENADE anos 2010 a 2019

\begin{tabular}{lc}
\hline \multicolumn{1}{c}{ Grupo de avaliação do ENADE } & Total de alunos por grupo \\
\hline $\begin{array}{l}\text { Bacharelados nas áreas de Saúde, Agrárias e áreas afins(anos de avaliação na } \\
\text { amostra: 2010, 2013, 2016 e 2019) }\end{array}$ & 121.595 \\
\hline $\begin{array}{l}\text { Bacharelados nas áreas de Ciências Exatas e áreas afins; e Licenciaturas (anos de } \\
\text { avaliação na amostra: 2011, 2014 e 2017) }\end{array}$ & 210.569 \\
\hline $\begin{array}{l}\text { Bacharelados nas áreas de Ciências Sociais Aplicadas, Ciências Humanas e áreas } \\
\text { afins (anos de avaliação na amostra: 2012, 2015 e 2018) }\end{array}$ & 96.011 \\
\hline Total & 428.175
\end{tabular}

Fonte: dados da pesquisa.

Ao analisar a variável custo corrente sem HU por aluno equivalente, observa-se, conforme Figura 3, que o custo corrente por aluno, em média, foi maior para as Ifes da região Sul do país. No ano de 2013, apresenta-se o mais alto valor médio no período analisado, que foi de $\mathrm{R} \$ 16.729,01$. Além disso, é possível observar que o custo corrente por aluno real (deflacionado) tem diminuído ao longo dos anos. No ano de 2010 , o custo médio por aluno somava $\mathrm{R} \$ 14.087,04$ e a partir do ano de 2014 nota-se uma queda expressiva desse valor,chegando a $\mathrm{R} \$ 6.785,55$ no ano de 2019. A redução no valor do custo por aluno no decorrer dos anos pode ter relação com o aumento da quantidade de alunos no ensino superior.Entretanto,esse fato aponta que o investimento na educação superior pública no Brasil tem decaído e não acompanha o crescimento da quantidade de alunos no ensino superior.

Outro possível motivo para a redução dos custos por aluno é a Emenda Constitucional n. 9 95/2016, que estipula limites para as despesas dos Orçamentos Fiscal e da Seguridade Social da União. Oliveira, Correa, Alencar, Crisóstomo e Catrib (2018) destacam que a regra de correção de gastos estipulada na emenda, baseada no total de despesas pagas no exercício anterior corrigidas pelo IPCA do período, inviabilizaria o funcionamento das Ifes no curto prazo. Os autores comentam que os gastos com investimentos nas instituições seriam os mais afetados. No estudo,são realizadas projeções para os anos de 2018 a 2022 que indicam que, devido ao crescimento dos gastos com pessoal, os limites estabelecidos pela emenda não permitiriam nem mesmo recompor a inflação do período para os grupos de despesas de custeio e investimento. Assim, conforme observado na Figura 3, a tendência de queda nos custos por aluno pode continuar nos próximos anos, impactando na qualidade da educação do ensino superior federal do país.

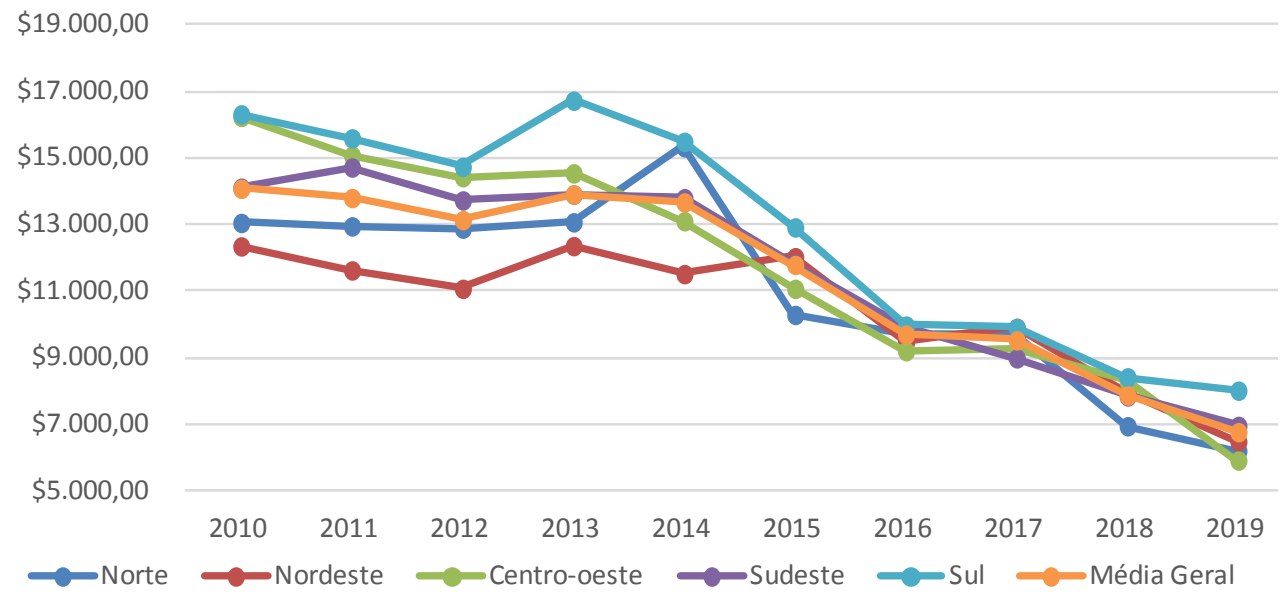

Figura 3. Evolução do custo corrente sem HU por aluno equivalente Fonte: dados da pesquisa. 
Para caracterizar o perfil das universidades brasileiras que compuseram a amostra, na Tabela 2 é apresentada a estatística descritiva das variáveis propostas para o modelo de regressão com dados em painel, compreendendo os anos de 2010 a 2019 para as 62 IES.Destaca-se também que nem todas as IES apresentaram dados para todo o período analisado, o que resultou em um painel de dados desbalanceado para análise. Os dados que são mostrados representam os resultados após o ajuste das observações consideradas como outliers por meio da técnica de winsorização.

Primeiramente, analisou-se a variável dependente do modelo, que é medida pela nota média dos alunos de cada IES no Enade. Verificou-se que, em média, os alunos das universidades obtiveram 51,01 pontos no Enade, sendo a dispersão dos dados baixa, já que o coeficiente de variação foi de $11 \%$. Como a nota máxima admitida pelo Enade é 100 pontos, observa-se que as notas dos discentes têm sido consideravelmente baixas, representando apenas $51 \%$ do total do exame. Mesmo a IES que alcançou a maior nota média no Enade $(68,77)$ ainda não pode ter sua pontuação considerada elevada.

Sobre os custos correntes sem HU por aluno, obteve-se a média de R $\$ 11.109,93$. Dessa forma, cada aluno custaria esse valorpor ano nas IES, sendo que nesse montante não são considerados os custos com hospitais universitários, aposentadorias e pensões, conforme descrição da variável utilizada e que os custos foram deflacionados pelo IPCA para refletir o real valor dos gastos realizados pelas IES no decorrer dos anos.Aponta-se que o custo por aluno obteve um desvio-padrão maior, mostrando que há universidades federais com níveis de custos por aluno distintos.

Com relação à idade dos estudantes, destaca-se que a média de idade foi de 26 anos, sendo $58 \%$, em média, do sexo feminino e $42 \%$, em média, do sexo masculino. Historicamente, a maioria dos estudantes do ensino superior eram homens. Entretanto, esse quadro vem mudando e as mulheres estão ganhando espaço nas universidades. Na última década, a representatividade das mulheres tem sido grande ao ponto de superar o número de homens nas universidades (Gil, 2018).Assim, observa-se que, com o passar do tempo, o paradigma cultural de que a mulher deve restringir-se à participação em determinados espaços está sendo rompido e, gradativamente, verifica-sesua inserção nos mais diversos ambientes sociais. A partir da constatação de que a maior parte da amostra do presente trabalho é composta por mulheres, fica evidente a trajetória histórica feminina na conquista por direitos iguais aos dos homens e na luta para colocá-los em prática.

Tabela 2

Estatística descritiva das variáveis propostas pelo estudo dados 2010 a 2019

\begin{tabular}{lcccccc}
\hline \multicolumn{1}{c}{ Variável } & Obs. & Média & $\begin{array}{l}\text { Desvio- } \\
\text { Padrão }\end{array}$ & $\begin{array}{c}\text { Coeficiente } \\
\text { de Variação }\end{array}$ & Mínimo & Máximo \\
\hline $\begin{array}{l}\text { Desempenho da universidade } \\
\text { (ENADE) }\end{array}$ & 558 & 51,01 & 5,51 & 0,11 & 41,29 & 60,71 \\
\hline Custo corrente sem HU (CUSTO) & 558 & $\mathrm{R} \$ 11.109,93$ & $\mathrm{R} \$ 3.403,31$ & 0,31 & $\mathrm{R} \$ 5.932,02$ & $\mathrm{R} \$ 18.966,59$ \\
\hline Idade (IDADE) & 558 & 26,14 & 1,60 & 0,06 & 23,85 & 29,68 \\
\hline Sexo Feminino (SEXFEM) & 558 & 0,58 & 0,09 & 0,16 & 0,41 & 0,75 \\
\hline Estado Civil Solteiro (SOLTEIRO) & 558 & 0,84 & 0,09 & 0,10 & 0,65 & 0,93 \\
\hline Raça/cor (RCBRANCA) & 558 & 0,54 & 0,23 & 0,42 & 0,04 & 0,96 \\
\hline Raça/cor (RCPRETA) & 558 & 0,08 & 0,05 & 0,64 & 0,01 & 0,23 \\
\hline Escolaridade da mãe (ESCMED) & 558 & 0,34 & 0,05 & 0,14 & 0,25 & 0,43 \\
\hline Escolaridade da mãe (ESCGRAD) & 558 & 0,22 & 0,08 & 0,34 & 0,10 & 0,36 \\
\hline Renda (RENDAATE1.5) & 558 & 0,17 & 0,10 & 0,56 & 0,04 & 0,39 \\
\hline Renda (RENDA1.5A3) & 558 & 0,23 & 0,07 & 0,31 & 0,10 & 0,36 \\
\hline Renda (RENDA3A4.5) & 558 & 0,17 & 0,04 & 0,21 & 0,10 & 0,24 \\
\hline Renda (RENDA4.5A6) & 558 & 0,12 & 0,03 & 0,27 & 0,06 & 0,18 \\
\hline
\end{tabular}

Fonte: dados da pesquisa. 
Em relação ao estado civil dos estudantes, na amostra observou-se $84 \%$ de solteiros e $11,7 \%$ de casados, outros estados civis como separado, divorciado, viúvo somaram juntos $4,3 \%$. O número expressivo de solteiros pode estar relacionado ao fato de grande parte dos alunos das Ifesserem jovens, muitos deles já entram na universidade após a conclusão do ensino médio.

$\mathrm{Na}$ amostra em questão, a raça declarada pelos alunos com maior média foi a branca, representando em média $54 \%$ dos estudantes, seguida pela raça parda com $33 \%$. Já os declarados pretos representaram $8,7 \%$. Os estudantes declarados de raça amarela, indígena e os que não declararam raça somaram aproximadamente $4,3 \%$.

Adicionalmente, avaliando os três grupos de áreas de aplicação do Enade, destaca-se que, no triênio de 2010 a 2012, os alunos declarados brancos representavam 60,7\%, pardos $30 \%$ e os pretos eram $6,78 \%$. Já no triênio de 2017 a 2019, os declarados brancos somavam 48,05\%, pardos 35,17\% e pretos 10,66\%. Assim, no decorrer do período analisado, o percentual de alunos brancos diminuiu e das raças preta e parda aumentou, o que pode representar uma tendência de maior diversidade e um possível efeito positivo das políticas de ações afirmativas no perfil dos alunos das universidades públicas federais.

Tal constatação está alinhada com as políticas de ações afirmativas de adoção das cotas para ingresso em cursos de graduação em universidades públicas federais, que leva em consideração a origem étnico-racial, renda e o fato de o candidato ter cursado todo o seu ensino médio em escolas públicas. Diante desse contexto, a Lei n. ${ }^{\circ} 12.711$, de 29 de agosto de 2012 e, posteriormente, a Lei n. ${ }^{\circ}$ 13.409 , de 28 de dezembro de 2016 , que garante a reserva de $50 \%$ das matrículas por curso e turno nas universidades federais e nos institutos federais de educação, ciência e tecnologia serão subdivididas: metade para estudantes de escolas públicas com renda familiar bruta igual ou inferior a um salário mínimo e meio per capita e metade para estudantes de escolas públicas com renda familiar superior a um salário mínimo e meio. Em ambos os casos, também será levado em conta percentual mínimo correspondente ao da soma de pretos, pardos e indígenas no estado, de acordo com o último censo demográfico do Instituto Brasileiro de Geografia e Estatística (IBGE).

Em 2018, de acordo com o IBGE (2019), 50,3\% dos estudantes do ensino superior se declararam pretos ou pardos, o que demonstra possíveis resultados advindos das ações afirmativas, apesar de os negros e pardos ainda estarem sub-representados, visto que constituíam $55,8 \%$ da população (IBGE, 2019). Desse modo, aspolíticas públicas voltadas especificamente para grupos histórica e socialmente excluídos em função de alguma característicadevem ser valorizadas, uma vez que tais aspectos são parte integrante e constitutiva de nossa sociedade.

Em relação à escolaridade da mãe, a maior parcela apontou que a mãe possui ensino médio completo (34\%), e, em seguida, graduação completa (22\%). Já em relação à renda dos estudantes, a maior parte dos alunos (23\%) declarou obter renda de 1,5 a 3 salários mínimos, 17\% declararam possuir renda de até 1 salário mínimo e outros $17 \%$ na faixa de 3 a 4,5 salários mínimos. Já o grupo de 4,5 a 6 salários mínimos representou $12 \%$ da amostra. Ao analisara evolução dos estudantes classificados em tais grupos de renda familiar, observa-se que,no triênio de 2010 a 2012, estudantes com renda familiar até 1,5 salário mínimo representavam 14,92\% dos estudantes e os de renda de 1,5 a 3 salários mínimos somavam 20,39\%. Juntos, esses estudantes representavam 35,31\% dos estudantes que realizaram o Enade. Nos anos de 2017 a 2019, esse grupo cresceu para $47,17 \%$, sendo $22,2 \%$ de renda familiar até 1,5 salário mínimo e $24,97 \%$ do grupo de 1,5 a 3 salários mínimos. Logo, percebe-se que, no período analisado, houve um aumento de estudantes com renda familiar de até 3 salários mínimos nas IES analisadas. Da mesma forma que para a raça, tal fato pode ser um resultado advindo das políticas de ações afirmativas adotadas pelas IES, a fim de incluir estudantes de baixa renda familiar no ensino superior. 
Por meio da estatística descritiva, constatou-se que no período de 2010 a2019 a maior parte dos estudantes das universidades públicas federais que realizaram o Enade era da raça branca, jovem, solteiro, do sexo feminino, com mãe que concluiu o ensino médio e renda entre 1,5 a 3 salários mínimos. Além disso, observou-se que as IES devem implementar políticas em busca de melhorar a nota dos discentes no Enade, incentivando os alunos e demonstrando a eles a importância desse exame, que muitas vezes é considerado como irrelevante para os estudantes.Ademais, apesar de um aumento no percentual de alunos pretos nas IES, o número ainda é muito baixo em relação às raças branca e parda, o que reforça a necessidade de políticas de ações afirmativas para o acesso aos alunos de raça preta no ensino superior.

\subsection{Análise dos índices-padrão do desempenho e dos custos correntes sem HU}

$\mathrm{Na}$ análise de índices-padrão foi considerada a média dos dados observados de cada Ifes referente às notas dos alunos no Enade (desempenho) e referente ao total do custo corrente sem HU por aluno. As Ifes foram classificadas em relação ao desempenho dos alunos, como excelente, bom, regular e satisfatório. Já em relação ao total docusto corrente sem HU por aluno, foram classificados como alto, médio, baixo e muito baixo. Ressalta-se que os dados analisados se encontram deflacionados.

Conforme pode-se observar na Figura 4, as Ifes que tiveram o desempenho excelente não apresentaram um comportamento uniforme em relação ao nível de custos. Destaca-se o caso da UFCSPA, que apresentou o maior desempenho em relação às IES da amostra, a qual obteve um nível muito baixo de custo por aluno. Contudo, a UFTM e UFRGS que também tiveram desempenho excelente, incorreram em níveis de custos distintos, alto e médio, respectivamente. Dentre as demais Ifesque apresentaram desempenho excelente, o comportamento dos custos manteve-se disperso, sendo que das dezesseis IES classificadas nesse grupo, seis (37,5\%) incorreram em um nível muito baixo de custos por aluno.

Quanto às universidades que apresentaram bom desempenho, o nível de custos não foi constante, sendo 33,3\% com nível alto, 20\% com nível médio, 33,3\% com nível baixo e 13,3\% com nível muito baixo.

No grupo de instituições com desempenho regular, prevaleceu o nível baixo de custos por aluno, sendo $33,3 \%$ das IES classificadas nesse nível. As demais representaram $26,4 \%$ em cada um dos níveis alto e médio e $13,3 \%$ no nível baixo.

Com relação às IES com desempenho insatisfatório no período analisado, o nível muito baixo de custos por aluno foi predominante, aparecendo em $37,5 \%$ das dezesseis IES do grupo. Além disso, no grupo tiveram ainda $18,8 \%$ de IES com nível alto, 31,2\% com nível médio e 12,5\% com nível baixo de custos por aluno. 


\begin{tabular}{|c|c|c|c|c|c|}
\hline \multirow{2}{*}{ IES } & Desempenho & Custo por Aluno & \multirow{2}{*}{ IES } & \multirow{2}{*}{$\begin{array}{l}\text { Desempenho } \\
\text { Classificação }\end{array}$} & \multirow{2}{*}{$\begin{array}{c}\text { Custo por Aluno } \\
\text { Classificação }\end{array}$} \\
\hline & Classificação & Classificação & & & \\
\hline UFCSPA & Excelente & MuitoBaixo & UFES & Regular & Baixo \\
\hline UFTM & Excelente & Alto & FURG & Regular & Baixo \\
\hline UFRGS & Excelente & Médio & UFF & Regular & Alto \\
\hline UFMG & Excelente & Baixo & UFVJM & Regular & Baixo \\
\hline UNB & Excelente & Alto & UFCG & Regular & Médio \\
\hline UFABC & Excelente & Alto & UFRRJ & Regular & Alto \\
\hline UFJF & Excelente & Médio & UFMT & Regular & Médio \\
\hline UNIRIO & Excelente & Baixo & UFOB & Regular & Alto \\
\hline UFSCAR & Excelente & Médio & UFPB & Regular & Médio \\
\hline UNIFEI & Excelente & Baixo & UFERSA & Regular & MuitoBaixo \\
\hline UFV & Excelente & Alto & UFMS & Regular & Baixo \\
\hline UFLA & Excelente & MuitoBaixo & UNIR & Regular & Médio \\
\hline UFC & Excelente & MuitoBaixo & UNIPAMPA & Regular & Alto \\
\hline UFPR & Excelente & MuitoBaixo & UFGE & Regular & Baixo \\
\hline UFCA & Excelente & MuitoBaixo & UFS & Regular & MuitoBaixo \\
\hline UNIVASF & Excelente & MuitoBaixo & UFRB & Insatisfatório & Médio \\
\hline UFOP & Bom & Baixo & UFRR & Insatisfatório & Alto \\
\hline UFBA & Bom & MuitoBaixo & UFAM & Insatisfatório & MuitoBaixo \\
\hline UFSM & Bom & Médio & UFRPE & Insatisfatório & Médio \\
\hline UFRN & Bom & Médio & UFPI & Insatisfatório & MuitoBaixo \\
\hline UFFS & Bom & Alto & UNILAB & Insatisfatório & Alto \\
\hline UTFPR & Bom & Baixo & UNIFAP & Insatisfatório & Médio \\
\hline UFSC & Bom & Médio & UFPA & Insatisfatório & MuitoBaixo \\
\hline UFRJ & Bom & Alto & UFAC & Insatisfatório & MuitoBaixo \\
\hline UNIFAL & Bom & MuitoBaixo & UFAL & Insatisfatório & MuitoBaixo \\
\hline UFPE & Bom & Baixo & UFRA & Insatisfatório & Baixo \\
\hline UNIFESP & Bom & Alto & UFT & Insatisfatório & Baixo \\
\hline UFG & Bom & Baixo & UNIFESSPA & Insatisfatório & Médio \\
\hline UFU & Bom & Baixo & UFSJ & Insatisfatório & MuitoBaixo \\
\hline UFPEL & Bom & Alto & UNILA & Insatisfatório & Alto \\
\hline UFMA & Bom & Alto & UFOPA & Insatisfatório & Médio \\
\hline
\end{tabular}

Figura 4. Classificação dos índices-padrão das IES por desempenho e custo corrente sem HU por aluno Nota: dados do período de 2010 a 2019.

Fonte: dados da pesquisa

Os dados apresentados na Figura 4 foram condensados para análise e interpretação, contudo, observando a base de dados ano a ano, em relação ao desempenho e custo corrente por aluno das Ifes, foi possível verificar que a universidade que atingiu a melhor nota foi a Universidade Federal de Ciências da Saúde de Porto Alegre(UFCSPA),com desempenho médio de69 pontos em 2018, sendo que no ano a IES incorreu em um custo corrente por aluno sem HU de R $\$ 7.477,96$. 
Por outro lado, a pior nota entre as Ifes em análise foi a da Universidade Federal da Integração Latino-Americana (Unila) em 2015, com média de aproximadamente 28 pontos. Ressalta-se que apesar de obter a pior nota no Enad e entre as universidades consideradas pela amostra, no mesmo ano a Unila alcançou um custo corrente sem $\mathrm{HU}$ por aluno de $\mathrm{R} \$ 19.452,96$. O alto valor dos gastos por aluno pode ser devido ao baixo número de discentes matriculados na universidade, pois a IES foi fundada em 2010, o que explicaria a baixa quantidade de estudantes, que em 2015 somavam apenas 870 alunos.

Conforme as análises dos índices-padrão, apesar de algumas predominâncias, não foi possível observar um comportamento homogêneo entre os níveis de desempenho e os níveis de custo por aluno das IES. No grupo de Ifes que apresentaram desempenho insatisfatório no Enade,predominou-se um nível muito baixo de custos por aluno. Contudo, apesar de ser esperado que as Ifes com desempenho excelente no Enad e tivessem um maior nível de custos, também prevaleceu no grupo o nível muito baixo de custos por alunode forma geral. Isso pode estar relacionado com o fato de que essas IES tenham maior desempenho no Enad e não apenas pelas condições institucionais, mas também pelo perfil dos alunos que ingressaram nas instituições (Ferreira, 2015). Outros fatores também poderiam estar relacionados aos níveis de custos e desempenho como, por exemplo, a gestão e aplicação de tais recursosou mesmo o engajamento dos alunos na realização do exame.

\subsection{Modelo empírico de regressão com dados em painel}

Como primeiro passo para a realização do modelo de regressão com dados em painel, foram realizados os testes de adequabilidade aos princípios do modelo de Mínimos Quadrados Ordinários (MQO). A multicolinearidade ficou entre os valores aceitos por Hair, Anderson e Tatham (2005), de 1 até 5, constatando-se, assim, multicolinearidade moderada. Já os testes RESET e de normalidade apontaram que a forma funcional é incorreta ou há omissão de alguma variável relevante e que a distribuição dos resíduos não é normal. Entretanto, o modelo é plausível de interpretação, pois, por se tratar de um modelo, não há como captar todas as variáveis que impactam no desempenho de um aluno de graduação. Sobre a normalidade dos resíduos, assumiu-se o teorema do limite central, que afirma que no limite os dados tenderão à normalidade.

Em seguida, procedeu-se aos testes para averiguar qual modelo era o mais adequado para a amostra:pooled, efeitos fixos ou efeitos aleatórios. Constatou-se que o modelo preferível éo de efeitos fixos. Posteriormente, realizouse os testes de heterocedasticidade e de autocorrelação, nos quais constatou-se a existência de heterocedasticidade e autocorrelação. Assim, estimou-se o modelo de regressão com dados em painel por meio de efeitos fixos e com consideração de existência de heterocedasticidade e autocorrelação por mínimos quadrados generalizados (GLS). Os resultados encontrados para os testes e o modelo estimado encontram-se na Tabela 3.

A variável foco deste estudo, os custos das universidades que foram medidos pelo custo corrente sem HU por aluno equivalente (CUSTOS), não foi significativa estaticamente, apontando ausência de relação entre o desempenho do aluno e custos correntes das IES da amostra.O resultado encontrado difere da relação esperada por este trabalho e dos achados dos estudos de Dahlvig et al. (2020), Rutherford e Rabovsky (2014), Pike et al. (2011) e Pike e Robbins (2019), os quais encontraram um efeito positivo em relação ao nível de despesa. No caso brasileiro, da mesma forma que os estudos internacionais, Barbosa et al. (2011) também encontraram relação positiva entre o custo por aluno e o desempenho no Enade. Contudo, o resultado corrobora os achados de Rocha e Funchal (2019) que não encontraram significância entre o desempenho do aluno e os gastos públicos, mas para o nível de ensino médio. Além disso, Hong e Zimmer (2016) destacam que o aumento no nível de despesas tem o potencial de melhorar o desempenho dos alunos, entretanto, esse efeito não é observado em um curto prazo. Os autores sugerem que tais gastos se materializem a partir de um prazo de 4 anos. 
Sobre as variáveis de controle, considerando o nível de significância de 5\%, as variáveis de idade, sexo feminino, estado civil solteiro, raça branca e renda de 1,5 a 3 salários mínimos foram significativas para explicar o desempenho. A idade apresentou um coeficiente positivo de 1,33, mostrando que alunos mais velhos tendem a obter nota melhor no Enade, confirmando a relação esperada pelo estudo. Santos (2012) também encontrou resultado positivo entre idade e desempenho no Enade. Uma explicação para esse resultado poderia ser o fato de pessoas mais velhas geralmente terem maior acúmulo de conhecimento prévio, ou mesmo maior experiência e comprometimento com a realização de exames.

Em relação ao sexo do discente, a literatura aponta que as mulheres, em média, têm melhor desempenho do que os homens (Rangel \& Miranda, 2016; Pike\&Robins, 2019). O resultado do estudo confirmou o apontado pela literatura, mostrando que quanto maior o número de mulheres realizando a prova, maior a tendência da nota média da universidade no Enadeaumentar, sendo que, no limite, se 100\% fossem mulheres, a média de pontuação seria maior em 23 pontos. Este achadocorrobora o estudo de Pike e Robbins (2019), que encontraram uma relação positiva entre o percentual de estudantes do sexo feminino e o desempenho delas na graduação. Entretanto, foi contrário ao resultado de Ferreira (2015), que constatou desempenho superior do sexo masculino no Enade. Entretanto, Ferreira (2015) avaliou apenas cursos de contabilidade.

Quanto ao estado civil dos estudantes, os resultados do modelo indicaram uma relação significativa e positiva no desempenho, sendo que, caso $100 \%$ dos alunos fossem solteiros, a média da nota aumentaria em 39,10 pontos. Esse resultado vai contra os achados de Santos (2012) e Ferreira (2015), os quais indicaram que o desempenho dos estudantes casados foi superior ao dos estudantes solteiros. Entretanto, Andrade e Corrar (2008) encontraram resultado congruente com o deste estudo. $\mathrm{O}$ fato de $\mathrm{o}$ estudante casado obter desempenho inferior ao solteiro pode ter relação com as responsabilidades que o indivíduo casado possui, como ser pai ou mãe, que podem interferir em seu tempo disponível para os estudos e, consequentemente, em seu desempenho acadêmico.

Sobre a raça do discente, os resultados apontaram que, se $100 \%$ dos alunos fossem brancos, a média da nota da universidade aumentaria em 6,95 pontos. Contudo, os resultados não indicaram uma relação significativa para a raça preta. Esses resultados são distintos de Rutherford e Rabovsky (2014), que indicaram uma relação negativa entre a raça dos estudantes negros e hispânicos e o desempenho. $\mathrm{O}$ resultado também se mostra contrário ao estudo de Pike e Robins (2019), que também indicaram uma relação negativa entre os percentuais de estudantes da raça negra e o desempenho na graduação. Todavia, este estudo está de acordo com os achados de Ferreira (2015), que afirma que alunos da raça branca tendem a ter desempenho superior ao de pardos e indígenas. Ferreira (2015) também encontrou que negros tendem a ter desempenho inferior aos brancos, o que contradiz este estudo.

A escolaridade da mãe do estudante também foi significativa estatisticamente, sendo que mães com escolaridade de nível médio e graduação apresentaram uma relação significativa com o desempenho. Assim, caso $100 \%$ das mães dos estudantes que realizaram a prova do Enad e tivesse como escolaridade máxima o ensino médio, a nota média aumentaria em 16,89 pontos e, caso $100 \%$ das mães dos estudantes que realizaram a prova do Enad e tivessem título de graduação, a nota média aumentaria em 30,28 pontos. Os achados deste estudo corroboram a relação esperada, que era de que quanto mais alto o nível educacional da mãe ou do responsável pelo aluno, maior o desempenho deste. Todavia, Ferreira (2015) encontrou resultado distinto ao deste trabalho, em que estudantes que possuem mãe que cursou ensino superior ou pós-graduação têm pior desempenho do que discentes que possuem mãe com escolaridade mais baixa. Um dos possíveis motivos para o melhor desempenho dos estudantes que possuem mães com maior nível de educação se dá pela influência que essas podem gerar na dedicação dos alunos aos estudos, incentivando-os a um melhor desempenho. 
Por fim, quanto à renda do estudante, foi possível observar uma relação positiva e estatisticamente significativa entre estudantes com renda familiar entre 1,5 a 3 salários mínimos e o seu desempenho. As demais faixas de renda não foram significativas. Embora fosse esperado que alunos com maior nível de renda familiar tivessem melhor desempenho, os resultados do modelo não indicaram tal relação. Este achado é contrário ao estudo de Ferreira (2015), no qual foi evidenciado que alunos com alta renda familiar tendem a apresentar um desempenho superior aos alunos de baixa renda. Contudo, Moreira (2010) encontrou que o desempenho de estudantes com renda familiar mais elevada é inferior em relação ao desempenho dos estudantes de renda familiar mais baixa. Uma possível explicação para estudantes de faixa de renda mais baixa terem desempenho superior a estudantes de faixa mais elevada pode ser a motivação daqueles nos estudos. Alunos com renda inferior podem enxergar a universidade como uma oportunidade de crescimento pessoal e profissional e, consequentemente, se dedicarem mais às atividades da IES. Ainda nessa linha, Diaz (2007) destaca que existe um limite no efeito proporcionado pela renda sobre o desempenho dos estudantes, ou seja, existe um ponto a partir do qual esse efeito torna-se decrescente.

Tabela 3

Resultados do modelo de regressão com dados em painel

\begin{tabular}{lcc}
\hline \multicolumn{1}{c}{ Variáveis } & Coeficiente & Valor-p \\
\hline Custo corrente sem HU (CUSTO) & $-0,00007$ & 0,18 \\
\hline Idade (IDADE) & 1,33 & 0,00 \\
\hline Sexo feminino (SEXFEM) & 23,38 & 0,00 \\
\hline Estado Civil (SOLTEIRO) & 39,10 & 0,00 \\
\hline Raça/cor (RCBRANCA) & 6,95 & 0,03 \\
\hline Raça/cor (RCPRETA) & 9,06 & 0,12 \\
\hline Escolaridade da mãe (ESCMED) & 16,89 & 0,00 \\
\hline Escolaridade da mãe (ESCGRAD) & 30,28 & 0,00 \\
\hline Renda (RENDAATE1.5) & $-3,37$ & 0,25 \\
\hline Renda (RENDA1.5A3) & 14,51 & 0,00 \\
\hline Renda (RENDA3A4.5) & $-4,56$ & 0,38 \\
\hline Renda (RENDA4.5A6) & 8,29 & 0,20 \\
\hline Constante & $-48,40$ & 0,00 \\
\hline Teste de Chow & & 0,00 \\
\hline Teste Breusch e Pagan & & 0,00 \\
\hline Teste de Hausman & & 0,00 \\
\hline Teste de Wooldridge para autocorrelação & 0,00 \\
\hline Testes de Wald para heterocedasticidade & & 0,00 \\
\hline Teste VIF para multicolinearidade & & 2,83 \\
\hline Teste Ramsey para especificação do modelo & 0,00 \\
\hline Doornik-Hansen & & 0,01 \\
\hline Fonte: dados da pesquisa. & & \\
\hline
\end{tabular}


Apesar da importância de saber as relações entre os gastos com educação e a aprendizagem dos estudantes, não foram obtidas evidências quanto a como os recursos podem promover os resultados esperados nas universidades. Considerando os resultados das variáveis referentes ao perfil sociodemográfico dos discentes e ao custo corrente por aluno pelas universidades, pode-se concluir, no caso desta amostra, que os fatores sociodemográficos têm maior impacto no desempenho do aluno do que os recursos que são aplicados pelas Ifes. Ferreira (2015) acredita que isso acontece devido ao perfil do aluno da universidade pública ser um perfil diferenciado, pois os discentes dessas IES tendem a ser mais aplicados nos estudos. Por outro lado, Pike et al. (2011) afirmam que os recursos aplicados nas universidades são indiretamente relacionados com os resultados esperados por parte dos discentes, uma vez quetais recursos possuem potencial de aprimorar, por exemplo, a qualificação docente da IES e, consequentemente, poderiam impactar no desempenho do estudante.

\section{Considerações Finais}

Tendo em vista um cenário de escassez de recursos das universidades federais, torna-se necessária a investigação dos impactos advindos da diminuição dos gastos nas IES. Entre os principais efeitos, encontrase a possível redução do desempenho escolar dos alunos. Dessa forma, este artigo buscou identificar a relação do nível de custo corrente por aluno das universidades federais com o desempenho acadêmico dos alunos de graduação. Para isso, foram analisadas 62 universidades federais brasileiras no período de 2010 a 2019.

Os resultados não mostraram relação entre o desempenho do discente e custos das IES. Dessa forma, a hipótese $\mathrm{H1}$ : Universidades públicas que incorrem em maiores custos correntes por aluno tendem a ter melhor desempenho no Enade, não foi confirmada.Por outro lado, os fatores sociodemográficos como idade, raça, sexo, estado civil, escolaridade da mãe e renda apresentaram uma relevante influência sobre o desempenho no Enade, concluindo-se que os fatores inerentes ao contexto do aluno têm maior influência sobre o seu desempenho do que os recursos investidos na universidade, confirmando os achados de Ferreira (2015).

Uma explicação para a irrelevância dos custos por aluno sobre o desempenho do estudante pode ser o fato de que o impacto no desempenho do aluno iria além da quantidade de recursos da IES, ou seja, dependeria também de uma boa gestão de tais recursos (Rocha \& Funchal, 2019). Além disso, Pike et al. (2011) indicam que os níveis de gastos das instituições de ensino superior teriam uma maior relação com o desempenho dos estudantes nos anos iniciais do curso. Assim, uma vez que a proxy de desempenho deste estudo foi o Enade, quem e de o conhecimento cumulativo do estudante em seu curso, outros resultados poderiam ser obtidos por meio da utilização de diferentes medidas de desempenho dos estudantes nos anos iniciais do curso. Outras peculiaridades das instituições analisadas também podem afetar o nível de custos, sendo que, talvez, a relação de tais custos e o desempenho dos alunos não esteja tão claramente associada. Dahlvig et al. (2020) acreditam que a relação entre recursos e desempenho dos alunos não seja direta ou linear, ou seja, a um certo ponto o incremento nos recursos já não faria efeito no desempenho dos alunos. Além disso,outras variáveis podem ser relevantes para a análise, pois podem afetar os custos ou mesmo o desempenho dos alunos, tais como: anos de fundação da instituição, localização, cursos ofertados, grau de instrução dos docentes, entre outros.

Como limitações da pesquisa, tem-se a falta de dados que permitissem separar os custos correntes por aluno em subgrupos. A separação dos custos em categorias proporcionaria a visualização mais completa dos gastos das universidades, como, por exemplo, os gastos com limpeza, energia, pessoal, entre outros, os quais podem ter impacto isolado no desempenho discente. Outra limitação da pesquisa é que apesar de o estudo ter analisado dados em relação ao Enade de 2010 a 2019, as edições do exame avaliam anualmente áreas distintas.Assim,destaca-se como uma limitação do estudo que as médias das notas podem ter sido afetadas no período analisado dadas as diferentes áreas de conhecimento avaliadas, bem como os diferentes cursos ofertados por cada IES da amostra. 
Do ponto de vista do ensino superior, é fundamental que as instituições saibam quais tipos de gastos têm maior probabilidade de produzir melhorias no desempenho dos estudantes (Pike\& Robbins, 2019). Diante disso, sugere-se que pesquisas futuras avaliem os níveis de custos e o desempenho específico de áreas de conhecimento como exatas, humanas, sociais, etc. Além disso, a adoção de outras proxies para os custos universitários que possibilitem análises específicas de grupos de custos poderia contribuir com discussões relevantes para a literatura. Dessa forma, um possível tema de estudo futuro poderia ser analisar o desempenho dos cursos da área de saúde considerando entre os determinantes os custos correntespor aluno incluindo os custos com HU,já que essa área de ensino usufrui da infraestrutura dos hospitais. Sugere-se também que estudos futuros utilizem outros modelos de estimação, adotando defasagens nas relações entre o nível de custos da IES e a nota dos alunos no Enade. Por fim, dados os diferentes níveis de infraestrutura e desenvolvimento das universidades, sugere-se que sejam consideradas em futuras pesquisas características como a idade da universidade, tipos de curso oferecidos (graduação, mestrado e doutorado) e proxies referentes à infraestrutura da instituição.

\section{Referências}

Andrade, J. X., \&Corrar, L. J. (2008). Condicionantes do desempenho dos estudantes de Contabilidade: evidências empíricas de natureza acadêmica, demográfica e econômica. Revista de Contabilidade da UFBA, 1(1), 62-74. Recuperado em 22 novembro, 2020, de https://portalseer.ufba.br/index.php/ rcontabilidade/article/view/2581

Araújo, E. A. T., Camargos, M. A., Camargos, M. C. S., \& Dias, A. T. (2013). Desempenho Acadêmico de Discentes do Curso de Ciências Contábeis: Uma análise dos seus fatores determinantes em uma IES Privada.Contabilidade Vista \& Revista,24(1), 60-83. Recuperado em 14 julho, 2019, de https:// revistas.face.ufmg.br/index.php/contabilidadevistaerevista/article/view/1181

Banco Mundial. (2017). Um ajuste justo: análise da eficiência e equidade do gasto público no Brasil. Washington, D.C.: BIRD/Banco Mundial. Recuperado em 11 maio, 2019, de https://www.worldbank. org/pt/country/brazil/publication/brazil-expenditure-review-report

Bandeira, M., Rocha, S. S., Freitas, L. C., Del Prette, Z. A. P., \& Del Prette, A. (2006). Habilidades sociais e variáveis sociodemográficas em estudantes do ensino fundamental. Psicologia em estudo, 11(3), 541-549. Doi: https://doi.org/10.1590/S1413-73722006000300010

Barbosa, G., Freire, F., \& Crisóstomo, V. (2011). Análise dos indicadores de gestão das IFES e o desempenho discente no ENADE. Revista da Avaliação da Educação Superior, 16(2), 317-343. Doi: https://doi. org/10.1590/S1414-40772011000200005

Braga, D. B., \& Franco, L. R. H. R. (2004). Revolucionando as técnicas de aprendizagem da engenharia com o EAD. In World Congress on Engineering and Technology Education, Guarujá, São Paulo, Brasil.

Brandão, A. S., Silva, A. T. B., \& Loureiro, S. R. (2017). The Predictors of Graduation: Social Skills, Mental Health, Academic Characteristics. Paidéia, 27(66), 117-125. Doi: https://doi.org/10.1590/198243272766201714

Chauí, M. (2003). A universidade pública sob nova perspectiva. Revista brasileira de educação, 24(1), 5-15. Doi: https://doi.org/10.1590/S1413-24782003000300002

Chiau, A. V., \& Panucci-Filho, L. (2014). Custos nas instituições federais de ensino superior: Análise comparativa entre duas Universidades Federais do Sul do Brasil. REICE, Revista Iberoamericana sobre Calidad, Eficaciay Cambio em Educación, 12(1), 55-71. Recuperado em 09 julho, 2019, de https://www.redalyc.org/pdf/551/55129541004.pdf 
Dahlvig, C. A., Dahlvig, J. E., \&Chatriand, C. M. (2020). Institutional expenditures and student graduation and retention. Christian Higher Education, 1-13. Doi: https://doi.org/10.1080/15363759.2020.1712561

Diaz, M. D. M. (2007). Efetividade no ensino superior brasileiro: aplicação de modelos multinível à análise dos resultados do Exame Nacional de Cursos. Revista EconomiA, 8(1), 93-120. Recuperado em 27 novembro, 2020, de http://anpec.org.br/revista/vol8/vol8n1p93_120.pdf

Eikner, A. E., \&Montondon, L. (2006). Evidence on factors associated with success in intermediate accounting I. The Accounting Educators' Journal, 13. Recuperado em 10 julho, 2019, de https:// www.researchgate.net/publication/268343070_Evidence_on_Factors_Associated_with_Success_ in_Intermediate_Accounting_I

Fagundes, C. V., Luce, M. B., \&Espinar, S. R. (2014). O desempenho acadêmico como indicador de qualidade da transição Ensino Médio-Educação Superior. Ensaio: Avaliação e Políticas Públicas em Educação, 22(84), 635-669. Doi: https://doi.org/10.1590/S0104-40362014000300004

Ferreira, M. A., (2015). Determinantes do desempenho discente no ENADE em cursos de ciências contábeis. Dissertação de Mestrado. Universidade Federal De Uberlândia. Uberlândia, MG, Brasil. Recuperado em 14 maio, 2019, de https://repositorio.ufu.br/bitstream/123456789/12620/1/ DeterminantesDesempenhoDiscente.pdf

Gil, A. C. (2018). Didática do Ensino Superior. (2a ed.). São Paulo: Atlas.

Hair, J. H. J., Anderson, R. E., \& Tatham, R.L. (2005). Análise Multivariada de Dados. (5a ed.). Porto Alegre: Bookman.

Hedges, L. V., Laine, R. D., \& Greenwald, R. (1994). An exchange: Part I: Does money matter? A metaanalysis of studies of the effects of differential school inputs on student outcomes. Educational researcher, 23(3), 5-14. Doi: https://doi.org/10.3102/0013189X023003005

Hong, K., \& Zimmer, R. (2016). Does Investing in School Capital Infrastructure Improve Student Achievement? Economics of Education Review,53(1) 143-158. Doi: https://doi.org/10.1016/j. econedurev.2016.05.007

Instituto Brasileiro de Geografia e Estatística - IBGE. (2019). Desigualdades sociais por cor ou raça no Brasil. Recuperado em 24 novembro, 2020, de https://biblioteca.ibge.gov.br/visualizacao/livros/ liv101681_informativo.pdf

Instituto Brasileiro de Geografia e Estatística - IBGE. (2020). Inflação. Recuperado em 24 novembro, 2020, de https://www.ibge.gov.br/explica/inflacao.php

Instituto Nacional de Estudos e Pesquisas Educacionais Anísio Teixeira - INEP. (2017). Censo da Educação Superior. Recuperado em 18 julho, 2019, de http://download.inep.gov.br/educacao_superior/censo_ superior/documentos/2018/censo_da_educacao_superior_2017-notas_estatisticas2.pdf

Instituto Nacional de Estudos e Pesquisas Educacionais Anísio Teixeira - INEP. (2019). ENADE. Recuperado em 5 julho, 2019, de http://inep.gov.br/enade

Instituto Nacional de Estudos e Pesquisas Educacionais Anísio Teixeira - INEP. (2020). Indicadores de Qualidade da Educação Superior. Recuperado em 30 dezembro, 2020, dehttps://www.gov.br/inep/pt-br/areas-deatuacao/pesquisas-estatisticas-e-indicadores/indicadores-de-qualidade-da-educacao-superior

Lei no 9.394, de 20 de dezembro de 1996. (1996). Lei das Diretrizes e Bases da Educação Nacional. Brasília. Recuperado em 16 junho, 2019, de http://www.planalto.gov.br/ccivil_03/LEIS/19394.htm

Lei $n^{\circ}$ 10.861, de 14 de abril de 2004. (2004). Institui o Sistema Nacional de Avaliação da Educação Superior - SINAES e dá outras providências. Recuperado em 4 junho, 2019, de http://www. planalto.gov.br/ccivil_03/_ato2004-2006/2004/lei/110.861.htmecial\%20denominado\%20 \%22Viol\%C3\%AAncia\%20Dom\%C3\%A9stica\%22 
Lei $n^{\circ}$ 12.711. de 29 de agosto de 2012. Dispõe sobre o ingresso nas universidades federais e nas instituições federais de ensino técnico de nível médio e dá outras providências. Recuperado em 15 junho, 2019, de http://www.planalto.gov.br/ccivil_03/_ato2011-2014/2012/lei/l12711.htm

Lei $n^{\circ} 13.409$, de 28 de dezembro de 2012. Altera a Lei no 12.711, de 29 de agosto de 2012, para dispor sobre a reserva de vagas para pessoas com deficiência nos cursos técnico de nível médio e superior das instituições federais. Recuperado em 26 novembro, 2020, de https:/www2.camara.leg.br/legin/fed/ lei/2016/lei-13409-28-dezembro-2016-784149-publicacaooriginal-151756-pl.html

Lemos, K. C. S.; \& Miranda, G. J., (2015). Alto e Baixo Desempenho no Enade: Que Variáveis Explicam? Revista Ambiente Contábil, 7(2), 101-118. Recuperado em 08 julho, 2019, de http://www.atena.org. br/revista/ojs-2.2.3-08/index.php/Ambiente/article/view/2469/2123

Lins, L. M. (2013). Educação e economia: um estudo da relação entre estrutura produtiva e demandas educacionais nas regiões metropolitanas de São Paulo e Belo Horizonte. Dissertação de mestrado, Universidade de São Paulo, São Paulo, SP, Brasil. Recuperado em 10 junho, 2019, de https://teses. usp.br/teses/disponiveis/8/8132/tde-13112013-111300/publico/2013_LeonardoMeloLins_VCorr.pdf

Magalhães, F. A. C., \& Andrade, J. X. (2006). Exame vestibular, características demográficas e desempenho na universidade: em busca de fatores preditivos. In Congresso USP de Controladoria e Contabilidade, São Paulo, São Paulo, Brasil. Recuperado em 28 maio, 2020, de https://congressousp.fipecafi.org/ anais/artigos62006/555.pdf

Martins, G. D. A., \&Theóphilo, C. R. (2009). Metodologia da investigação cientifica para Ciências Sociais Aplicadas (2a ed.). São Paulo: Atlas.

Masasi, N. J. (2012). How personal attribute affect students' performance in undergraduate accounting course: A case of adult learner in Tanzania. International Journal of Academic Research in Accounting, Finance and Management Sciences, 2(2), 201-211.

Matarazzo, D. C. (2008). Análise financeira de balanços: abordagem básica e gerencial. (6ª ed.). São Paulo: Atlas.

Miranda, G. J., Lemos, K. C. S., Oliveira, A. S., \& Ferreira, M. A. (2015). Determinantes do desempenho acadêmico na área de negócios. Revista Meta: Avaliação, 7(20), 175-209. Doi: https://doi. org/10.22347/2175-2753v7i20.264

Moreira, A. M. D. A. (2010). Fatores institucionais e desempenho acadêmico no ENADE: um estudo sobre os cursos de biologia, engenharia civil, história e pedagogia.Tese de Doutorado, Universidade de Brasília, Brasília, DF, Brasil. Recuperado em 27 novembro, 2020, de https://repositorio.unb.br/ handle/10482/8663

Moura, M. (2019) Universidades públicas respondem por mais de 95\% da produção científica do Brasil. Blog, Política Científica e Tecnológica. Recuperado em 25 novembro, 2020, de https://ciencianarua.net/universidadespublicas-respondem-por-mais-de-95-da-producao-cientifica-do-brasil/.

Oliveira, J. C. K., Correa, D. M. M. C., Alencar, R. C., Crisostomo, V. L., \&Catrib, A. M. F. (2018). Estudo Preditivo do Impacto Orçamentário da Emenda Constitucional No 95/2016 nas Universidades Federais Brasileiras. In: XXI Semead - Seminários em Administração, São Paulo, São Paulo, Brasil. Recuperado em 05 janeiro, 2021, de https://login.semead.com.br/21semead/anais/resumo.php?cod_trabalho=2201

Pike, G. R., \& Robbins, K. R. (2019). Using Panel Data to Identify the Effects of Institutional Characteristics, Cohort Characteristics, and Institutional Actions on Graduation Rates. Research in Higher Education, 61(1), 485-509. Doi: https://doi.org/10.1007/s11162-019-09567-7

Pike, G. R., Kuh, G. D., McCormick, A. C., Ethington, C. A., \& Smart, J. C. (2011). If and when money matters: The relationships among educational expenditures, student engagement and students' learning outcomes. Research in Higher Education, 52(1) 81-106. Doi: https://doi.org/10.1007/ s11162-010-9183-2 
Pike, G. R., Smart, J. C., Kuh, G. D., \& Hayek, J. C. (2006). Educational expenditures and student engagement: When does money matter? Research in Higher Education, 47(7), 847-872. Doi: https:// doi.org/10.1007/s11162-006-9018-3

Powell, B. A., Gilleland, D. S., \& Pearson, L.C. (2012). Expenditures, efficiency, and effectiveness in U.S. undergraduate higher education: a national benchmark. The Journal of Higher Education, 83(1), 102-127. Doi: https://doi.org/10.1353/jhe.2012.0005

Rangel, J. R., \& Miranda, G. J. (2016). Desempenho Acadêmico e o Uso de Redes Sociais. Sociedade, Contabilidade e Gestão, 11(2), 139-154. Doi: http://dx.doi.org/10.21446/scg_ufrj.v11i2.13383

Reis, E. A.; \& Reis, E. A. (2013). Sistemas de informação e tomada de decisão na gestão universitária: um olhar nos indicadores de desempenho de uma instituição de ensino superior. In Coloquio De Gestión Universitaria En Américas, Florianópolis, Santa Catarina, Brasil. Recuperado em 21 maio, 2019, de https://repositorio.ufsc.br/handle/123456789/114689

Rocha, A. B., \& Funchal, B (2019). Mais recursos, melhores resultados? As relações entre custos escolares diretos e desempenho no Ensino Médio. Revista de Administração Pública, 53(2) 291-309. Doi: https://doi.org/10.1590/0034-761220170175

Rutherford, A., \&Rabovsky, T. (2014). Evaluating Impacts of Performance Funding Policies on Student Outcomes in Higher Education. The ANNALS of the American Academy of Political and Social Science, 655(1), 185-208. Doi: https://doi.org/10.1177/0002716214541048

Santos, N. A. (2012). Determinantes do desempenho acadêmico dos alunos dos cursos de ciências contábeis. Tese de Doutorado, Universidade de São Paulo, São Paulo, SP, Brasil. Recuperado em 16 maio, 2020, de https://www.teses.usp.br/teses/disponiveis/12/12136/tde-11062012-164530/publico/ NalbiadeAraujoSantosVC.pdf

Schultz, T. W. (1960). Capital formation by education. The Journal of Political Economy, 68(6), 571-583. Doi: http://dx.doi.org/10.1086/258393

Tribunal de Contas da União - TCU. (2010). Orientações para o cálculo dos indicadores de gestão. Recuperado em 25 novembro, 2020, de https:/wp.ufpel.edu.br/proplan/files/2016/03/manual_tcu.pdf.

Webber, D. A., \& Ehrenberg, R. G. (2010). Do expenditures other than instructional expenditures affect graduation and persistence rates in American higher education?Economics of Education Review, 29(6), 947-958. Doi: https://doi.org/10.1016/j.econedurev.2010.04.006 